\title{
Wage Difference Between Formal Sector and Informal Sector Jobs; With Special Reference to the Labour Market in Sri Lanka
}

\author{
${ }^{1}$ Bharatha Prabath Parakrama Badullahewage, \\ ${ }^{2}$ Shohani Upeksha Badullahewage \\ ${ }^{1}$ Department of Statistics, Faculty of Sciences, \\ University of Colombo, Sri Lanka \\ ${ }^{2}$ Department of Economics, Faculty of Humanities and Social Sciences, \\ University of Sri Jayewardenepura, Sri Lanka
}

\begin{abstract}
It is globally understood that wage-based employment structure and wages are a central aspects of the labour force at work. The informal sector is ranging to a broader concept that is difficult to define. The formal-informal wage gap is crucial to understand labour market informality, especially in developing countries with the large informal sectors. The basic model is taken from Mincer (1974), and the study is primarily based on secondary data. The new dummy variable of Job_type and an interactive term were incorporated into the Mincer earning function to analyse wage differences between formal sector and informal sector jobs. The study concludes that there is a wage gap between the a formal and informal sector. Moreover, if a person engages in formal sector job with good education qualification and good working experience, he will be entitled for a higher wage rate. Policies that promote education and equal opportunities for workers in both formal and informal sectors would improve earnings for many workers by increasing productivity and incomes.
\end{abstract}

Keywords: Difference, Formal, Informal, Jobs, Wage.

\section{Introduction}

It is globally understood that wage-based employment structure and wages are a central aspects of the labour force at work. The informal sector is ranging to a broader concept that is difficult to define. According to ILO, the poor working class and its activities includes the informal sector who are not recognized, recorded, secured, and regulated by public authorities. Maloney (2004) argues that the informal sector cannot be marginalised because it might be a voluntary choice for individuals or businesses due to various factors like aversion of tax, cost of regulations, having greater flexibility and more freedom.

\subsection{Problem Statement}

Formal employment is recognised of workers with social security benefits provided by the employer, while informal employment refers to its absence. The organized sector consists of considerably regular workers although on an informal basis, workers includes both regular and casual workers. The informal sector include largely casual employment (Papola \& Kannan, 2016). The formal-informal wage gap is crucial to understand labour market informality, especially in developing countries with large informal sector. It is widely accepted that both formal and informal sectors play a key role in the global economy.

\subsection{The Main Objective of the Study}


Bharatha Prabath Parakrama Badullahewage, Shohani Upeksha Badullahewage

Wage Difference Between Formal Sector and Informal Sector Jobs; With Special Reference to the Labour Market in Sri Lanka

The Main objective of the study is to investigate the wage difference between the formal and informal sectors and the extent of such difference in Sri Lankan labour market.

\section{Literature Review}

\subsection{Theoretical Review}

The wage is measured as returns to education, and it is estimated using two main methods in the literature, that is, the full-discounting method and the Mincerian earnings function. Research references over the years have given preference for researchers to apply the Mincerian method because of its convenience (Psacharopoulos \& Patrinos, 2018).

Differences in earnings across different socio-economics categories are assessed by adding categorical dummy variables to the basic Mincer earnings. In fact, in many empirical studies, the Mincer earnings function has been modified to incorporate region, union membership status, city size, race, gender, ethnicity, migration status, health status, tenure on the job, and a host of other factors that could affect earnings (Polachek, 2008).

The rate of return to schooling equates the value of lifetime earnings of the individual to the net present value of education costs. The rate of return should have a positive value for an investment to be justified economically and should be higher than the alternative rate of return. An individual point of view, weighing costs and benefits means in investment if the rate of return exceeds the private discount rate (the cost of borrowing and an allowance for risk). The costs incurred by the individual are the foregone earnings while studying, plus any schooling fees or incidental expenses incurred. The private benefits are assessed on how much extra an educated individual earns (after taxes) compared to an individual with less education. Society's spending on education refers to the social rate of return - for example, money spent on renting buildings and professorial salaries. The estimated rate of return in terms of social attribute refers to the inclusion of the full resource cost of the investment - the direct costs by government and the foregone earnings of students as they invest in their education. The costs are higher in a social rate of return calculation, so comparing relatively to the one from the private point of view, social returns are typically lower than a private rate of return.

Mincer (1974) initiated to derive firstly an empirical equation of earnings over the lifecycle. In Mincer Earning function, at any point $(t)$ in an individual's lifetime, observed earnings [which equals potential earnings $w K(t)$ minus human capital investment $(1 s(t)) K(t)]$ can be depicted as a concave function of one's labour market experience. Assuming that the schooling phase of investment lasts $S$ years and that on-the-job training declines linearly over the lifecycle, logearnings are a quadratic function of labour market experience. In $Y=\alpha 0+\alpha 1 S+\alpha 2 X+\alpha 3 X 2+\mu$ $Y(t)=w K(t)-s(t) K(t)$

- $\alpha 0$ is related to initial earnings capacity,

- $\alpha 1$ is the rate of return to education (assuming all schooling costs as opportunity-costs)

- $\alpha 2$ and $\alpha 3$ are related to both the amount and the financial return to on-the-job training The Mincerian earnings function has been the subject of controversy in the literature (Psacharopoulos and Layard, 1979; Heckman, Lochner, and Todd, 2006). One issue with the Mincerian method of estimating returns to education is missing variables, e.g. ability bias. Griliches (1977) analysed the issue many years ago. He found that the bias is small or negative. Adding more variables to the equation will not solve the problem and might add other biases (Patrinos, 2016).

The earnings premium associated with the level of education suggests that productivity increases as people acquire additional qualifications. An alternative view is that earnings increase with education due to credential effects. This refers to the idea that higher levels of schooling are associated with higher earnings, not because they directly raise productivity, but because they certify that the worker is likely to be productive. In this sense, education merely sorts workers according to their unobserved attributes; it does not necessarily augment their intrinsic productivity. Moreover, The Mincerian method gives private returns, whereas the full discounting method can give private and social returns. 


\subsection{Empirical Review}

Economists have studied the wage gap between formal-informal sectors to establish the facts whether informal workers earn less than their formal counterparts. Alternative theories have been put forward to explain this phenomenon. The traditional labour theory argues that workers choose the informal sector because they are limited to the entry of formal sector due barriers (Fields, 1990; Harries \& Todaro, 1970).

Henley, Arabsheibani, and Carneiro (2006) found from the study contents in Brazil that informal workers on average tend to earn less than their formal counterparts. Tannuri and Pianto (2002) point out in the entire wage distribution in Brazil that a positive wage gap is in favour of formal workers. The study results done in Brazil, South Africa and Mexico by Bargain and Kwenda (2009) also indicate a significant formal-informal wage gap at lower quantiles. Sookram and Watson (2008) say that formal sector workers earn more than informal sector workers and work experience is the important determinant of the wage gap in Caribbean islands Trinidad and Tobago.

Polachek (2008) confirm the positive correlation between schooling and earnings based on the data of 2003 Current Population Survey to assess rates of return to education across occupational categories in the U.S. labour market. They find that "additional schooling" has a positive impact on the weekly earnings of men and women in both white- and blue-collar occupations.

Gong and van Soest (2002) apply quarterly panel data from Mexico in the analysis of the wage differentials between formal and informal sectors. They use random effects wage regression to explain the wage formation and differentials, thus managing likely selection bias because of unobserved time-invariant heterogeneity which affects both wages and sector choice. This is the first such study to determine simultaneously wages and sector choice in one dynamic panel data setting. Using Heckman (1981)'s Monte Carlo simulated maximum methodology, Gong and van Soest point out that age significantly affects formal sector wage, not the informal sector wage. Although much higher returns to education show in the formal sector, returns seem positive in both sectors. The lagged labour market state has no effect on wages and random effects are insignificant in the wage determination process. For testing formal-informal wage differentials divide in Argentina, Pratap, and Quintin (2006) prefer to propensity matching score methodology (PSM) to find the sample selection problem often inherent in such analyses. As in line with other studies, they find a 25 percent formal wage premium using standard OLS estimation, controlling for individual and establishment characteristics. However, once semiparametric methods are matched in observation of similar workers, Pratap and Quintin find no evidence of a formal-sector wage premium and thereby reject the segmented formal-informal Argentinian style labour markets theory. They evaluate the firm importance of controlling firm size in their last section of analysis, worker characteristics which are unobserved may affect both selection decision and wages and the value of other pecuniary and non-pecuniary benefits of a job.

The informal-formal wage gap is examined by Bargain and Kwenda (2009) using large panels in Brazil, Mexico, and South Africa. The study is twofold. First, usual measures of wage are adjusted for the taxes paid in the formal sector likely to cause overestimation of the same sector wage premium. Secondly, time-invariant unobserved heterogeneity is accounted for by using fixed-results quantile regression estimation of Koenker (2004) and Canay (2011). The sample is included only urban male aged 15-65 not having in any form of education, working as unpaid family or public worker. Females are excluded from the sample given that most are engaged in unpaid family work and accounting for selection into labour market is not yet standard in quantile regressions. The findings reveal a similar distributional pattern of informal wage penalty across all countries, as resulting informal wage gap prevails mostly in lower earnings quantiles and disappears at the top quantiles. Blunch (2011) adds to the existing facts by examining the magnitude and determinants of formal-informal sectors earnings gap in Serbia even amidst in the recent International Financial Crisis. The empirical analysis is carried out and referred to across four alternative measures of informality (firm registration, labour contract, benefit 
Bharatha Prabath Parakrama Badullahewage, Shohani Upeksha Badullahewage

Wage Difference Between Formal Sector and Informal Sector Jobs; With Special Reference to the Labour Market in Sri Lanka

receipts and firm size) and two time periods of 2008 and 2009. In particular, Blunch first estimates the raw formal-informal sectors earnings gap through Mincer wage regressions using ordinary least squares, then applies overall and detailed Blinder-Oaxaca decompositions to the observed earning gaps. The findings evince a large formal-informal sectors earnings gap which somehow appears to decrease following the onset of the crisis. However, the gap does not show a noticeable change when controlled for observable characteristics.

\section{Research Methodology}

The basic model is taken from Mincer (1974). The study is primarily based on secondary data and the sample size is equal to 1705 .

In $Y=\alpha 0+\alpha 1 S+\alpha 2 X+\alpha 3 X 2+\mu$

where $\operatorname{In} Y$ is the $\log$ value of the rate of return to education, $S$ is the years of schooling, $X$ is equal to total years of experience and $X 2$ is the square value of experience.

In this study new dummy variable, Job_type (formal sector or informal sector jobs) and an interactive term were incorporated into the Mincer earning function to analyse wage difference between formal sector and informal sector jobs.

In $Y=\alpha 0+\alpha 1 S+\alpha 2 X+\alpha 3 X 2+\alpha 4 D+\alpha 5(S D)+\mu$

$D$ is a dummy variable (formal sector and informal sector) and SD is an interactive term (years of schooling multiply by dummy variable. $\alpha 4$ measures the effect on intercept (Average) and $\alpha 5$ measures effect on rate of returns to education (wage) When $D=0$ (person from informal sector)

In $Y=\alpha 0+\alpha 1 S+\alpha 2 X+\alpha 3 X 2$

When $D=1$ (person from formal sector)

In $Y=(\alpha 0+\alpha 4)+(\alpha 1+\alpha 5) S+\alpha 2 X+\alpha 3 X 2$

The following variables were selected from the data set given to estimate the model.

EPF - Employer has registered under EPF or Inland Revenue Department

Age - Age of the person

Formal - Maintain accounts

Income - Total income from all sources in both primary and secondary jobs Education - Years of schooling

Table 3.1: Variables used for model estimation.

\begin{tabular}{|l|l|l|l|}
\hline Variable & Label & $\begin{array}{l}\text { Type of the } \\
\text { variable }\end{array}$ & Derivation of variable \\
\hline In $\mathrm{Y}$ & Log_income & Continuous & Log value of the income \\
\hline $\mathrm{S}$ & Education & Continuous & Years of schooling \\
\hline $\mathrm{X}$ & Experience & Continuous & Age $-\mathrm{S}-6$ \\
\hline $\mathrm{X} 2$ & $\begin{array}{l}\text { Square value of the variable } \\
\text { experience }\end{array}$ & Continuous & $X 2$ \\
\hline $\mathrm{D}$ & $\begin{array}{l}\text { Type of the job } \\
\mathrm{D}=1=\text { Formal sector jobs } \\
\mathrm{D}=0=\text { Informal sector jobs }\end{array}$ & Dummy & $\begin{array}{l}\mathrm{D}=1 \text { if } \mathrm{EPF}=1 \text { and if formal }=1 \mathrm{D} \\
=0 \text { if EPF }=0 \text { and if formal }>1\end{array}$ \\
\hline SD & Interactive term & Continuous & $\mathrm{S}^{*} \mathrm{D}$ \\
\hline
\end{tabular}

\subsection{The Rationale for Constructing the Dummy Variable ( $D=$ Type of the Job)}

As per the definitions given by the ILO and Census and Statistics Department, the formal sector jobs refer to any employer who maintains formal accounts, contributing to EPF, paying taxes and provide many social security benefits to the employees. In contrast, informal sector jobs refer to people who work on casual basis and they do not maintain any formal accounts, paying 
Bharatha Prabath Parakrama Badullahewage, Shohani Upeksha Badullahewage Wage Difference Between Formal Sector and Informal Sector Jobs; With Special Reference to the Labour Market in Sri Lanka

taxes or contributing to EPF. Thus, by considering the given data set, the variable "D" is constructed based on both formal and EPF variables.

\subsection{Data Cleaning - Handling Missing Values}

Improper handling of missing values will lead to draw an inaccurate inference about the data. In fact, the researcher may have two options either to drop the missing data or replace them by mean or mode value. In this study, the number of missing values of the constructed dummy variable (D) is 1295 and it is quite a large proportion out of the total sample size. As mentioned above, there are two possible remedies either to drop the missing values or replace them by the mode value (because $D$ is a dummy variable). Since, the main objective of the study is to detect whether is difference in wage between formal and informal sector jobs, replacing 1295 missing values will lead to draw a biased result. Even after deducting the missing values, the total sample is equal to 1705 which is sufficient to run log-linear regression analysis. Thus, the best possible remedy is to omit missing values from the data set.

\section{Regression Analysis}

Regression model: $\quad \ln Y=\alpha 0+\alpha 1 S+\alpha 2 X+\alpha 3 X 2+\alpha 4 D+\alpha 5(S D)+\mu$

\section{Data Analysis and Interpretation}

\subsection{Descriptive Statistics}

Table 4.1: Descriptive Statistics of variables.

\begin{tabular}{|c|c|c|c|c|c|c|c|}
\hline Variable & Mean & Std. dev & Std. error & \multicolumn{2}{|c|}{ [95\% Conf. Interval] } & Min & Max \\
\hline S & 10.162 & 3.432 & 0.082 & 9.388 & 9.709 & 0 & 17 \\
\hline $\mathrm{X}$ & 23.352 & 14.099 & 0.360 & 22.256 & 23.669 & -1 & 66 \\
\hline $\mathrm{X} 2$ & 744.030 & 769.879 & 19.646 & 709.775 & 786.839 & 0 & 4356 \\
\hline In_Y & 10.084 & 0.699 & 0.017 & 9.956 & 10.022 & 6.908 & 13.122 \\
\hline D & 0.581 & 0.494 & 0.012 & 0.858 & 0.604 & 0 & 1 \\
\hline SD & 6.188 & 5.754 & 0.140 & 5.914 & 6.461 & 0 & 17 \\
\hline
\end{tabular}

Source: Author constructed, 2020.

The mean value of the log income is 10.08 and its standard deviation is 0.699 . The mean of an interactive term (SD) is 6.188 and its standard deviation is 5.754. Education and experience report 10.162 and 23.352 mean values, respectively.

Chart 4.1: Mean comparison of wage between formal sector vs informal sector.

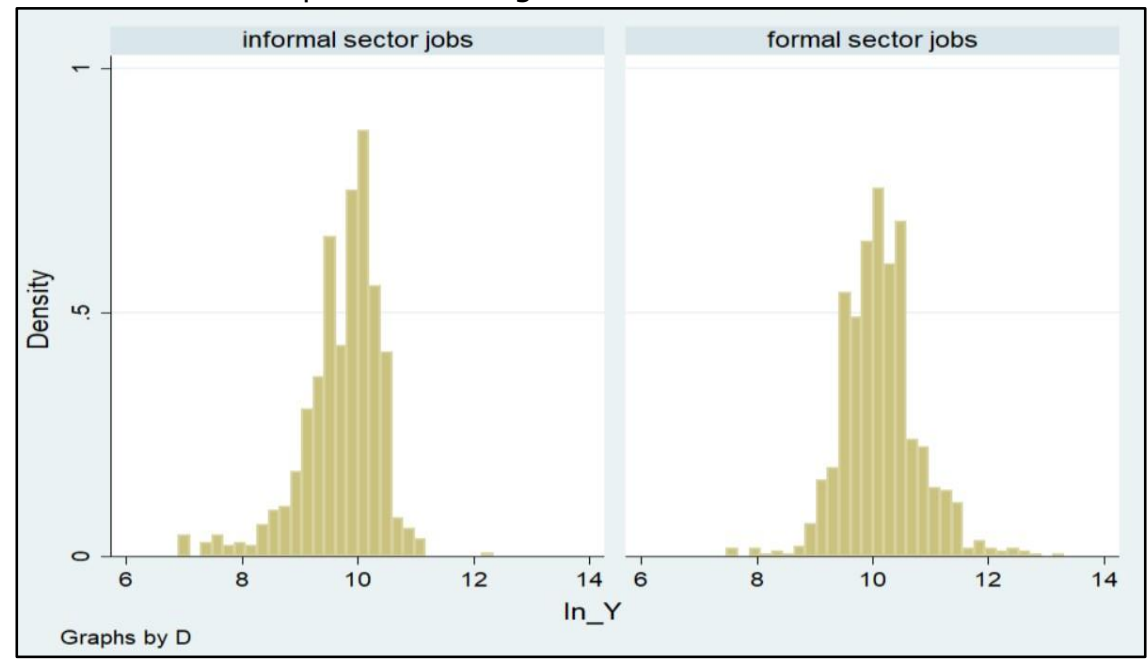


Bharatha Prabath Parakrama Badullahewage, Shohani Upeksha Badullahewage Wage Difference Between Formal Sector and Informal Sector Jobs; With Special Reference to the Labour Market in Sri Lanka

Table 4.2: Regression results of corrected and uncorrected models.

\begin{tabular}{|c|c|c|c|c|c|c|}
\hline \multirow[b]{2}{*}{ Variable } & \multicolumn{3}{|c|}{ Uncorrected Model } & \multicolumn{3}{|c|}{$\begin{array}{l}\text { Corrected Model } \\
\text { (The model is adjusted for } \\
\text { Heteroscedasticity and } \\
\text { Multicollinearity) }\end{array}$} \\
\hline & Coefficient & Std. error & $P>t$ & Coefficient & Std. error & $P>t$ \\
\hline$\alpha_{0}$ (constant) & 9.3167 & 0.084 & 0.000 & 9.3187 & 0.084 & 0.000 \\
\hline$\alpha_{1}(\mathrm{~S})$ & 0.0085 & 0.008 & 0.271 & 0.0086 & 0.008 & 0.271 \\
\hline$\alpha 2(\mathrm{X})$ & 0.0348 & 0.001 & 0.006 & 0.0345 & 0.003 & 0.000 \\
\hline$\alpha_{3}(\mathrm{X} 2)$ & -0.0006 & 0.000 & 0.000 & -0.0006 & 0.000 & 0.000 \\
\hline$\alpha_{4}$ (D) & -0.6587 & 0.035 & 0.000 & -0.6587 & 0.933 & 0.000 \\
\hline$\alpha_{5}(\mathrm{SD})$ & 0.1012 & 0.009 & 0.000 & 1.1012 & 0.009 & 0.000 \\
\hline$F(5,1699)$ & & 114.12 & & & 114.12 & \\
\hline Pob $>F$ & & 0.000 & & & 0.000 & \\
\hline R-squared & & 0.2514 & & & 0.2514 & \\
\hline Adjusted R-squared & & 0.2492 & & & 0.2492 & \\
\hline
\end{tabular}

Source: Author constructed, 2020.

\subsection{Interpreting the Results of an Uncorrected Model}

R2 and Adj. R2 indicate the Coefficient of Determination and its adjusted value, respectively. These explain the proportion of total variation of $Y$ explained by the regression, but Adj. R2 is more accurate than R2. As per the regression results R2 $=0.2510$ and Adjusted $\mathrm{R} 2=0.2492$ which means that the independent variables, explain $25 \%$ of the variability of the dependent variable (In_Y) which is quite insufficient. However, the regression model is statistically significant, $F(5,1699)=114.12, p=0.0000$. This indicates that, overall, the model applied can statistically significantly predict the dependent variable, wage.

In $Y=\alpha 0+\alpha 1 S+\alpha 2 X+\alpha 3 X 2+\alpha 4 D+\alpha 5(S D)$

$\ln Y=9.3167+0.0086(S)+0.0348(X)-0.0006(X 2)-0.6587(D)+0.1012(S D)$

Since $\alpha 1$ is not statistically significant $(p=0.271>0.05)$, it is omitted from the estimated model. Regression results of uncorrected regression model;

$\ln Y=9.3167+0.0348(X)-0.0006(X 2)-0.6587(D)+0.1012(S D)$

$\alpha 3$ measures the effect on intercept (Average) and $\alpha 5$ measures effect on rate of returns to education (wage)

When $D=0$ (person from informal sector)

In $Y=\alpha 0+\alpha 1 S+\alpha 2 X+\alpha 3 X 2$

$\ln Y=9.3167+0.0086(S)+0.0348(X)-0.0006(X 2)$

Since $\alpha 1$ is not statistically significant $(p=0.271>0.05)$

$\ln Y=9.3167+0.0348(X)-0.0006(X 2)$

When $\mathrm{D}=1$ (person from formal sector)

$\ln Y=(\alpha 0+\alpha 4)+(\alpha 1+\alpha 5) S+\alpha 2 X+\alpha 3 X 2 \ln Y=8.658+0.1098(S)+0.0348(X)-0.0006$ $(X 2)$

Since $\alpha 1$ is not statistically significant $(\mathrm{p}=0.271>0.05)$, the coefficient of $\mathrm{S}(\alpha 1+\alpha 5)$ is calculated only by considering the $\alpha 5$.

$\ln Y=8.658+0.1012(S)+0.0348(X)-0.0006(X 2)$

The significant positive coefficient for SD $(p=0.000<0.05)$ indicates that there is a significant difference of rate return to education (wage) between formal and informal sector jobs. A person engaged in formal sector jobs receives $10 \%$ ( In $\mathrm{Y}$ increase by 0.1012 when $\mathrm{D}=1$ ) higher wage 
Bharatha Prabath Parakrama Badullahewage, Shohani Upeksha Badullahewage Wage Difference Between Formal Sector and Informal Sector Jobs; With Special Reference to the Labour Market in Sri Lanka

rate than the person who is engaged in informal sector job. The magnitude of the effect over the rate return to education is much higher for person engaged in formal sector job.

If a person engages in informal sector job; education does not affect for determining wage rate, but increase in years of experience will increase the wage rate by $3 \%$. But, if a person engage in formal sector job; increase years of schooling (S) by one unit will increase wage rate by $10 \%$ $(0.1012)$ and increase in years of experience will increase the wage rate by $4 \%(0.0348)$. Thus, if a person engages in formal sector job with good education qualification and good working experience, he will be entitled for higher wage rate. The results of the study indicate that the education and work experience will increase magnitude over wage rate for formal sector job holder. Moreover, work experience has positive impact over wage rate of informal sector job holder, whereas education has no any significant impact.

\subsection{Second Order Tests}

Table 4.3: Test results of Multicollinearity and Heteroscedasticity.

\begin{tabular}{|l|l|l|}
\hline Variable & VIF & $\mathbf{1}$ /VIF \\
\hline SD & 14.1 & 0.070928 \\
\hline X2 & 12.53 & 0.079837 \\
\hline X & 12.35 & 0.080995 \\
\hline D & 9.94 & 0.100594 \\
\hline S & 3.26 & 0.306289 \\
\hline Chi2 (1) & 11.24 & \\
\hline Prob > chi2 & 0.0008 & \\
\hline
\end{tabular}

Source: Author constructed, 2020.

Since VIF value of SD is 14.10 and $X 2$ is 12.53 ; Multicollinearity between $X$ and $X 2$ and between $\mathrm{S}$ and SD are at harmful level. Prob $>\mathrm{CHI} 2=0.0008$ indicates that the null hypothesis is rejected. This means the model estimated above is contaminated with Heteroscedasticity.

Adjustment for the problem of Heteroscedasticity; White correction of Error Variance.

The robust was conducted to adjust the problem of Heteroscedasticity and coefficients are slightly differ than the uncorrected model.

\subsection{Mathematical Adjustment for the Problem of Multicollinearity}



$\alpha 0=\theta 0-\alpha 3 \delta 0-\alpha 5 \delta 2$

$\boldsymbol{\alpha} \mathbf{0}=9.5894-(-0.0006 *(-451.2403))-(0.1012 *(-1.23 e-13))=9.5894-0.2707-0=$ 9. 3187 
Bharatha Prabath Parakrama Badullahewage, Shohani Upeksha Badullahewage

Wage Difference Between Formal Sector and Informal Sector Jobs; With Special Reference to the Labour Market in Sri Lanka

$\alpha 2=\theta 2-\alpha 3 \delta 1$

$\alpha 2=0.0032-(-0.0006 * 52.2394)=0.0032-(-0.0313)=\mathbf{0 .} 0345$

$\alpha 4=\theta 3-\alpha 5 \delta 3$

$\boldsymbol{\alpha 4}=0.4197-(0.1012 * 10.6565)=0.4197-1.0784=-\mathbf{0 . 6 5 8 7}$

Regression results of corrected regression model;

$\ln Y=9.3187+0.0086 S+0.0345 X-0.0006 X 2-0.6587 D+0.1012 S D$

Since $\alpha 1$ is not statistically significant $(p=0.271>0.05)$, it is omitted from the estimated model.

$\ln Y=9.3187+0.0345 X-0.0006 X 2-0.6587 D+0.1012 S D$

Table 4.4: Comparison of Corrected Model with uncorrected model.

\begin{tabular}{|c|c|c|}
\hline & Estimates of uncorrected Model & $\begin{array}{c}\text { Estimates of corrected } \\
\text { Model }\end{array}$ \\
\hline$\alpha_{0}$ & 9.3167 & 9.3187 \\
\hline$\alpha_{1}$ & 0.0085 & 0.0086 \\
\hline$\alpha_{2}$ & 0.0348 & 0.0345 \\
\hline$\alpha_{3}$ & -0.0006 & -0.0006 \\
\hline$\alpha_{4}$ & -0.6587 & -0.6587 \\
\hline$\alpha_{5}$ & 0.1012 & 1.1012 \\
\hline
\end{tabular}

Source: Author Constructed, 2020.

\subsection{Interpreting the Results of a Corrected Model}

When $\mathrm{D}=0$ (person from informal sector)

In $Y=\alpha 0+\alpha 1 S+\alpha 2 X+\alpha 3 X 2 \ln Y=9.3187+0.0086 S+0.0345 X-0.0006 X 2$

Since $\alpha 1$ is not statistically significant $(p=0.271>0.05)$

$\ln Y=9.3187+0.0345 X-0.0006 X 2$

When $\mathrm{D}=1$ (person from formal sector)

$\ln Y=(\alpha 0+\alpha 4)+(\alpha 1+\alpha 5) S+\alpha 2 X+\alpha 3 X 2 \ln Y=8.660+0.1098(S)+0.0345(X)-0.0006$ $(X 2)$

Since $\alpha 1$ is not statistically significant $(\mathrm{p}=0.271>0.05)$, the coefficient of $\mathrm{S}(\alpha 1+\alpha 5)$ is calculated only by considering the $\alpha 5$.

$\ln Y=8.660+0.1012(S)+0.0345(X)-0.0006(X 2)$

The significant positive coefficient for SD $(p=0.000<0.05)$ indicates that there is a significant difference of rate return to education (wage) between formal and informal sector jobs. A person engaged in formal sector jobs receives $10 \%$ (In $\mathrm{Y}$ increase by 0.1012 when $\mathrm{D}=1$ ) higher wage rate than the person who is engaged in informal sector job. The magnitude of the effect over the rate return to education is much higher for person engaged in formal sector job.

If a person engages in informal sector job; education does not affect for determining wage rate, but increase in years of experience will increase the wage rate by $3 \%$. But, if a person engage in formal sector job; increase years of schooling (S) by one unit will increase wage rate by $10 \%$ $(0.1012)$ and increase in years of experience will increase the wage rate by $3 \%(0.0345)$. Thus, 
Bharatha Prabath Parakrama Badullahewage, Shohani Upeksha Badullahewage Wage Difference Between Formal Sector and Informal Sector Jobs; With Special Reference to the Labour Market in Sri Lanka

if a person engages in formal sector job with good education qualification and good working experience, he will be entitled for higher wage rate. The results of the study indicate that the education and work experience will increase magnitude over wage rate for formal sector job holder. Moreover, work experience has positive impact over wage rate of informal sector job holder, whereas education has noa any significant impact.

Log-Linear Regression Model - an extension to a mincer earning function is used to analyse whether the return on education (wage) is differed between formal and informal sector jobs.

In $Y=\alpha 0+\alpha 1 S+\alpha 2 X+\alpha 3 X 2+\alpha 4 D+\alpha 5(S D)$

$H 0 ; \alpha 4=\alpha 5=0$

Since, sig value for $\alpha 4$ is 0.000 ( $p=0.000<0.05)$ and sig value for $\alpha 5$ is $0.000(p=0.000<$ $0.05), H O$ is rejected, concluding that there is significance difference of rate of return to education between formal and informal sector jobs. A person engaged in formal sector jobs receives $10 \%$ ( In $\mathrm{Y}$ increase by 0.1012 when $\mathrm{D}=1$ ) higher wage rate than the person who is engaged in informal sector job.

\subsection{Estimates Of Corrected Regression Model}

Since $\alpha 1$ is not statistically significant $(p=0.271>0.05)$

$\ln Y=9.3187+0.0086 S+0.0345 X-0.0006 X 2-0.6587 D+0.1012 S D$

$\ln Y=9.3187+0.0345 X-0.0006 X 2-0.6587 D+0.1012 S D$

When $\mathrm{D}=0$ (person from informal sector)

$\ln Y=\alpha 0+\alpha 1 S+\alpha 2 X+\alpha 3 X 2 \ln Y=9.3187+0.0086 S+0.0345 X-0.0006 X 2$

$\ln Y=9.3187+0.0345 X-0.0006 X 2$

When $\mathrm{D}=1$ (person from formal sector)

$\ln Y=(\alpha 0+\alpha 4)+(\alpha 1+\alpha 5) S+\alpha 2 X+\alpha 3 X 2 \ln Y=8.660+0.1098(S)+0.0345(X)-0.0006$ $(X 2)$

$\ln Y=8.660+0.1012(S)+0.0345(X)-0.0006(X 2)$

The study estimates that there is significant difference of rate return to education (wage) between formal and informal sector jobs. A person engaged in formal sector jobs receives higher wage rate than the person who is engaged in informal sector job. If a person engages in informal sector job; work experience has positive impact on wage rate. Moreover, if a person engages in formal sector job with good education qualification and good working experience, he will be entitled for higher wage rate. Thus, the magnitude of the effect over the rate return to education is much higher for person engaged in formal sector job.

\section{Conclusion and Recommendations}

The study concludes that there is a wage gap between the formal and the informal sector. The findings of this paper suggest that human capital factors i.e., education and experience have a key role in improving the wages. The higher educated and more experienced workers are likely to have higher earnings in the formal sector. Policies that promote education and equal opportunities for workers in both formal and informal sectors would improve earnings for many workers by increasing productivity and incomes.

\section{Acknowledgements}

The authors are grateful to senior lecturer panel in the Department of Economics and Department of Statistics for their support and encouragement and thanks to the officers in the Department of Census and Statistics for their valuable support in this regard. 
Bharatha Prabath Parakrama Badullahewage, Shohani Upeksha Badullahewage

Wage Difference Between Formal Sector and Informal Sector Jobs; With Special Reference to the Labour Market in Sri Lanka

\section{References}

- Bargain, O., \& Kwenda, P. (2009). The informal sector wage gap: New evidence using quantile estimations on panel data (IZA Discussion Paper No. 4286).

- $\quad$ Fields, G. (1990). Labour market modelling and the urban informal sector: Theory and evidence. In D. Turnham, B. Salome, \& A. Schwartz (Eds.), The informal sector revisited (pp. 49-69). Paris: OECD.

- Griliches, Z. (1977). "Estimating the Returns to Schooling: Some Econometric Problems." Econometrica 45: 1-22. doi:10. 2307/1913285 Crossref

- Harries, J., \& Todaro, P. M. (1970). Migration, unemployment, and development: A two-sector analysis. The American Economic Review, 60(1), 126-142.

- Heckman, J. J., Lochner, L. J., and Todd, P.E., (2006). "Earnings Functions, Rates of Return and Treatment Effects: The Mincer Equation and Beyond." In Handbook of the Economics of Education (Volume 1), edited by E. Hanushek, and F. Welch, 307-458. Amsterdam: Elsevier. Crossref

- Henley, A., Arabsheibani, G. R., \& Carneiro, F. G. (2006). On defining and measuring the informal sector (World Bank Policy Research Working Paper No. 3866). Crossref

- Kahyalar, N., Fethi, S., Katircioglu, S., \& Ouattara, B. (2018). Formal and informal sectors: is there any wage differential?. The Service Industries Journal, 38(11-12), 789-823. doi:

10.1080/02642069.2018.1482877 Crossref

- Maloney, W. F. (2004). Informality revisited. World Development, 32(7), 1159-1178. Crossref

- Mincer, J. A. (1974). Schooling, Experience, and Earnings. New York: National Bureau of Economic Research.

- $\quad$ Murphy, K., \& Welch, F. (1990). Empirical Age-Earnings Profiles. Journal of Labour Economics, 8(2), 202-229 Crossref

- Patrinos, H. A. (2016). "Estimating the Return to Schooling Using the Mincer Equation." IZA World of Labour 2016. Crossref

- Polachek, S. (2008). Earnings Over the Life Cycle: The Mincer Earnings Function and Its Applications (IZA Discussion Paper No. 3181) Crossref

- Psacharopoulos, G., \& Patrinos, H. (2018). Returns to investment in education: a decennial review of the global literature. Education Economics, 26(5), 445-458. doi: 10.1080/09645292.2018.1484426 Crossref

- Psacharopoulos, G., and R. Layard. 1979. "Human Capital and Earnings: British Evidence and Critique." The Review of Economic Studies 46: 485-503. doi:10.2307/2297015 Crossref 
Bharatha Prabath Parakrama Badullahewage, Shohani Upeksha Badullahewage Wage Difference Between Formal Sector and Informal Sector Jobs; With Special Reference to the Labour Market in Sri Lanka

- Sookram, S., \& Watson, P. (2008). The informal sector poverty and gender in the Caribbean: The case of Trinidad \& Tobago. Journal of Eastern Caribbean Studies, $33(4), 43-68$.

- Tannuri, E. M., \& Pianto, M. D. (2002). Informal employment in Brazil - A choice at the top and segmentation at the bottom: A quantile regression approach (University of Brasilia Department of Economic Working Paper No. 236). 